\title{
TOMOSVARYELLA ACZÉL DO MÉXICO, AMÉRICA CENTRAL E ANTILHAS (DIPTERA, PIPUNCULIDAE)
}

\author{
Rosaly Ale-Rocha ${ }^{1}$ \\ José Albertino Rafael ${ }^{1}$
}

\begin{abstract}
TOMOSVARYELLA ACZÉl From MEXICO, CENTRAL AMERICA AND Antilles (Diptera, Pipunculdidae). Fifteen species of Tomosvaryella (Diptera, Pipunculidae) from Mexico, Central America and Antilles are registered. Two new species from Mexico are deseribed: $T$. membranacea and $T$. mexicanensis. Four species are redeseribed from the types; a new synonym is stablished: Tomosvaryella ttumida Hardy, 1940=Pipunculus lynchi Shannon, 1927. A key based in males is included.

KEY WORDS. Diptera. Pipunculidae, Tomosvaryella, taxonomy
\end{abstract}

Os representantes da família Pipunculidae são pequenos, escuros, de asas longas e cabeça hemisférica ocupada quase completamente pelos olhos compostos. Durante o estágio larval são endoparasitóides de Auchenorrhyncha (Homoptera) (WALOFF \& JERVIS 1987). Uma classificação genérica da família foi feita recentemente (RAFAEL \& DE MEYER 1992), e informações sobre a biologia do grupo são encontradas em KOIZUMI (1959), YANO (1979) WALOFF \& JERVIS (1987).

O gênero Tomosvaryella Aczél, 1939 é talvez o mais altamente especializado e abundante da família (HARDY 1943) e distingue-se de outros pipunculídeos pelos seguintes caracteres: cerdas propleurais, pterostigma e veia $\mathrm{M}_{2}$ ausentes, veia $\mathrm{r}-\mathrm{m}$ localizada no meio ou próximo ao meio da seção superior da célula $\mathrm{dm}$. O gênero é cosmopolita e as espécies são muito semelhantes entre si, separadas principalmente por caracteres da terminália e trocanter posterior dos machos. As larvas são endoparasitóides exclusivas de Deltocephalinae, Cicadellidae (Homoptera) (DE MEYER 1989).

Durante a revisão das espécies neotropicais de Tomosvaryella foram examinados vários espécimens do México, América Central e Antilhas. Até o momento, duas espécies haviam sido registradas para o México, duas para a América Central e cinco para as Antilhas. Com a descrição de duas espécies novas e novos registros, a região tratada neste trabalho inclui agora 15 espécies conhecidas.

1) Coordenaçāo de Pesquisas em Entomologia. Instituto Nacional de Pesquisas da Amazônia (INPA). Caixa Postal 478. 69011-970 Manaus, Amazonas, Brasil. Bolsista do CNPq. 


\section{MATERIAL E MÉTODOS}

Foram examinados os holótipos de todas as espécies, com exceção de $T$. dissimilis, da qual cinco parátipos foram examinados, e T. polita.

O material estudado provém das seguintes instituições: California Academy of Sciences (CAS), San Francisco, E.U.A.; American Museum of Natural History (AMNH), Nova Iorque, E.U.A.; Academy of Natural Sciences of Philadelphia (ANSP), Philadelphia, E.U.A.; The Natural History Museum (BMNH), Londres, Inglaterra; Field Museum of Natural History (FMNH), Chicago, E.U.A; Museum of Comparative Zoology (MCZ), Cambridge, E.U.A.; National Museum of Natural History (USNM), Smithsonian Institution, Washington DC, E.U.A; Snow Entomological Museum (SMEK), University of Kansas, Kansas, E.U.A.

As espécies com descrições originais incompletas foram redescritas; quanto às outras, foram feitas apenas descrições sucintas com ênfase nos caracteres diferenciais. Para espécies com o abdome já dissecado, recorreu-se à descrição original. As variações observadas são apresentadas separadamente. A terminália e as pernas, depois de desprendidas do corpo, foram acondicionadas em microtúbulo com glicerina, afixado no mesmo alfinete do espécime.

A terminologia segue o trabalho de MCALPINE (1981). Neste trabalho, os termos direito e esquerdo para os surstilos, correspondem aos surstilos interno e externo, respectivamente. As informações acrescidas em "Material Examinado" que não constavam na(s) etiqueta(a) do(s) espécime(s) foram colocadas entre colchetes.

\section{RESULTADOS E DISCUSSÃO}

Chave para as espécies de Tomosvaryella Aczél do México, América Central e Antilhas, baseada em machos.

1. Sintergoesternito 8 simétrico, sub-hemisférico; trocanter posterior com processo ventral curto e achatado apicalmente; abdome semiclavado . . . . . . . . subvirescens

- Sintergoesternito 8 assimétrico, comprimido para a direita (Figs 7, 15, 22, 30);

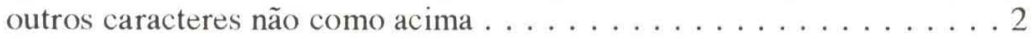

2. Trocanter posterior com processo ventral espiniforme $\ldots \ldots \ldots \ldots$

- Trocanter posterior com processo ventral de forma variada, não espiniforme

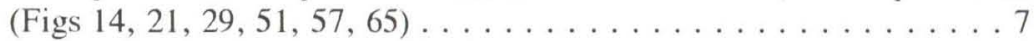

3. Trocanter posterior com dois processos espiniformes (Fig. 6) . . . . bidens

- Trocanter posterior com processo espiniforme único (Figs 1, 36, 71) . . . .4

4. Cercos longos, protuberantes, densamente pilosos (Fig. 38); saco espermático do apódema ejaculador dilatado (Fig. 41); surstilos semi-simétricos com ápices afilados (Fig. 37) . . . . . . . . . . . . sachtlebeni

- Cercos não como acima; saco espermático normal . . . . . . . . . 5 
5. Fêmur posterior com protuberância sub-basal desenvolvida (Figs 1, 71),

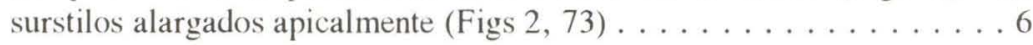

- Fêmur posterior sem protuberância sub-basal desenvolvida, surstilos curtos (Fig. $45) \ldots \ldots \ldots \ldots \ldots \ldots \ldots \ldots \ldots \ldots \ldots \ldots \ldots \ldots \ldots \ldots \ldots \ldots$ dissimilis

6. Fêmur posterior espessado; tarsos posteriores fortemente alargados e achatados

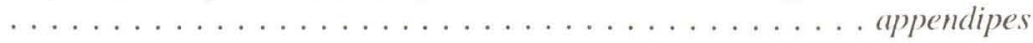

- Fêmur posterior não distintamente espessado, tarsos posteriores estreitos . tuberculata

7 (2). Trocanter posterior com processo curto, quase quadrado, (Fig. 57); sintergoesternito 8 longo; cercos subdivididos em quatro lóbulos (Fig. 60) sonorensis

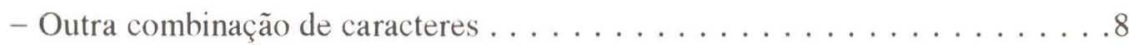

8. Trocanter posterior abaulado ventralmente com cerdas fortes (Fig. 51); surstilos grandes, semi-simétricos, com ápices truncados e face dorsal convexa (Fig.

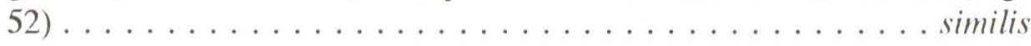

- Trocanter posterior em forma de monte com ápice afilado ou arredondado (Figs $14,42,65$ ); surstilos variáveis . . . . . . . . . . . 9

9. Espécies grandes, robustas, acima de $3,0 \mathrm{~mm}$ de comprimento; face posterior do fềmur posterior com cerdas alongadas e delgadas . . . . . . . . 10

- Espécies geralmente menores; face posterior do fêmur posterior com cerdas

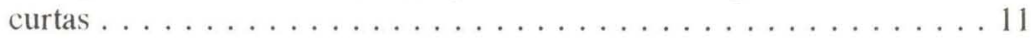

10. Sintergoesternito 8 largo, área membranosa larga; surstilos estreitos, levemente dilatados e truncados apicalmente (Fig. 24); ápice do parâmero longo com dois espinhos dorsais fortes e iguais (Fig. 26); membrana desenvolvida envolvendo o edeago (Fig. 27) . . . . . . . . . . . membranacea

- Sintergoesternito 8 estreito; surstilos longos e delgado com ápices curvados para dentro, não dilatados (Fig. 32); ápice do parâmero com um espinho dorsal delgado; ramo dorsal do edeago com fileira de pequenos espinhos (Fig. 34) mexicanensis

11 (9). Surstilos curtos, robustos, com protuberância dorsal cerdosa (Fig. 45) . . $\ldots \ldots \ldots \ldots \ldots \ldots \ldots \ldots \ldots \ldots \ldots \ldots \ldots \ldots \ldots \ldots \ldots \ldots \ldots$

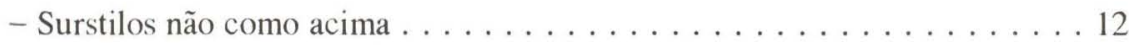

12. Surstilos alargados apicalmente (Fig. 17); ápice do parâmero curto (Fig. 19) lynchi

- Surstilos variáveis; ápice do parâmero longo (Fig. 68) . . . . . . . . 13

13. Surstilos com ápices em pinça, angulosos na base (Fig. 66) . . . . spangleri

- Surstilos, em vista lateral, com ápices tão ou mais largos que a base, quase retos dorsalmente e truncados apicalmente . . . . . . . galapagensis 
Tomosvaryella polita (Williston, 1896), descrita de Saint Vincente, Antilhas, não foi incluída na chave de identificação devido à sua descrição original incompleta, que não permite seu reconhecimento. O tipo está provavelmente perdido.

\section{Tomosvaryella appendipes (Cresson, 1911)}

Figs $1-5$

Pipunculus appendipes Cresson, 1911:319.

Tomosvaryella appendipes: Hardy, 1943: 150. Figs 81a-h (redescrição). - Aczél, 1948: 18 (distribuição). - Hardy. 1965a: 855 (catálogo).

Holótipo macho. Corpo 2,7mm; asa 2,4mm.

Corpo brilhante, tórax e abdome com pruinosidade castanha, cerdas torácicas e escutelares inconspícuas, terceira seção costal cerca de 1/3 da quarta, lobo anal desenvolvido, pernas brilhantes, trocanter posterior com processo espiniforme delgado e curvo em direção à base (Fig. 1), fềmur posterior espessado com protuberância sub-basal desenvolvida, tarsos posteriores fortemente alargados e achatados, surstilos estreitos na base, alargados e truncados apicalmente (Figs 2, 3), parâmero com ápice curto, ramificações do edeago curtas (Fig. 4), apódema ejaculador como na figura 5 .

Fêmea. Descrita por HaRdY (1943).

Registros geográficos. E.U.A., México (novo registro).

Material tipo examinado. [U.S.A.], Summerville, S[outh| C|arolina], 7.2.[19|06 (Holótipo macho, ANSP). Condição do holótipo: perna posterior esquerda e abdome em microtúbulo com glicerina.

Outros espécimens examinados. MÉxico, San Luis Potosí: El Bonito, (7mi. S. of Ciudad Valles, el. 300'), 19-XII-1970, P.H. \& M. Arnaud leg. (três machos, CAS); 20-XII-1970 (três machos, CAS; um macho, INPA).

Observação. Os surstilos divergem ligeiramente da figura apresentada por HARDY (1943).

Discussão. Espécie muito próxima de $T$. tuberculata. Difere por ter os tarsos posteriores distintamente dilatados e achatados com os tarsômeros 2 a 4 mais largos que longos; fêmur posterior dilatado com tubérculo sub-basal mais desenvolvido que em $T$. tuberculata.

\section{Tomosvaryella bidens (Cresson, 1911)}

Figs 6-13

Pipunculus bidens Cresson, 1911: 320 .

Tomosvaryella bidens; Hardy, 1943: 153, Figs 83a-f (redescrição, deserição fêmea). - Aczél, 1948: 10. 19. 26 (distribuição); 1952: 248 (catálogo), - Hardy. 1965b: 65. Figs 25a-d (breve descrição); 1966: 8 (catálogo). - Scarbrough \& Knutson, 1989: 526 (chave).

Holótipo macho. Corpo 2,7mm; asa 2,6mm.

Corpo preto, brilhante, tórax com pruinosidade castanha, cerdas torácicas inconspícuas, trocanter posterior com dois processos espiniformes ventrais (Fig. 

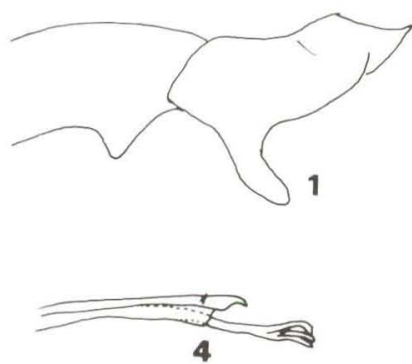

4
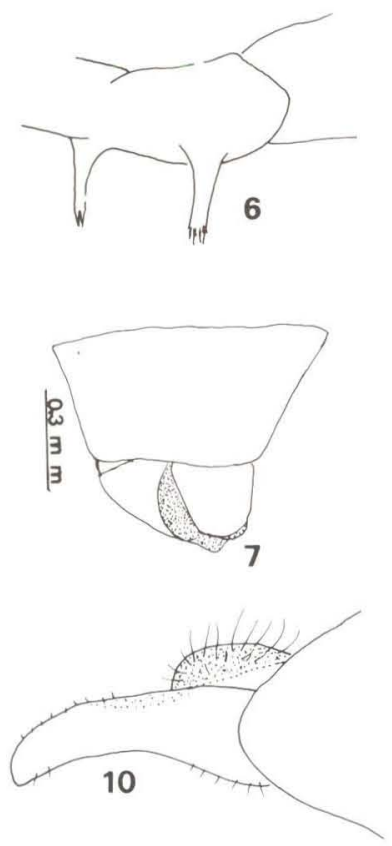

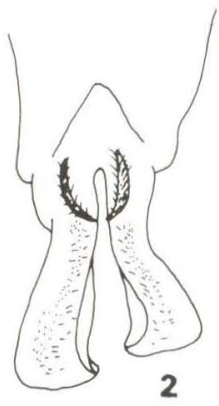

2
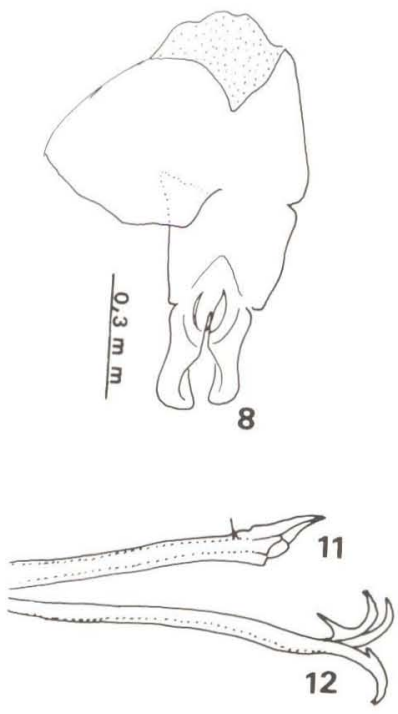

Figs 1-13. (1-5) Tomosvaryella appendipes, holótipo macho. (1) Trocanter posterior; (2) surstilos; (3) surstilo direito, lateral; (4) parâmero e edeago; (5) apódema ejaculador. (6-13) Tomosvaryella bidens, holótipo macho. (6) Trocanter posterior; (7) terminália dorsal; (8) terminália ventral; (9) surstilos; (10) surstilo direito, lateral; (11) parâmero; (12) edeago; (13) apódema ejaculador. Figuras 1-6, 9-13 na mesma escala.

6), tarso posterior levemente achatado, terminália em vista dorsal e ventral como nas figuras 7 e 8 respectivamente, surstilos semi-simétricos (Figs 9, 10), parâmero simples com pequeno espinho dorsal (Fig. 11), ramo dorsal do edeago com espinho sub-basal desenvolvido (Fig. 12), apódema ejaculador como na figura 13.

Fêmea. Descrita por HARDY (1943).

Registros geográficos. E.U.A, México, El Salvador (novo registro), Bahamas (novo registro), Brasil. 
Material tipo examinado. [U.S.A.], California, Yosemite Valley, 22.v.[19]08, Cresson (Holótipo macho n ${ }^{\circ}$ 5031, ANSP); Berkeley Hill (Parátipo macho, ANSP). Condição do holótipo: abdome em microtúbulo com glicerina.

Outros espécimens examinados. México, Nuevo León: Chipinque Mesa (4300 ft.), 20-IX-1975, J.A. Chemsak, J.A.Powell (um macho, CAS); San Luis Potosí: El Bonito (7 mi. S. of Ciudad Valles, el. 300'), 20-XII-1970, P.H. \& M. Arnaud leg. (um macho, CAS); Baja Callifornia: Sur (Isla San José, 1 mi S. Punta Colorado), 8-9-IV-1974, John T. Doyen leg., Ex Malaise Trap (um macho, CAS). El SALvadoR, Cerro Verde (6800'): 29-VI-1966, D.Q.Cavagnaro \& M. E.Irwing leg. (um macho, CAS). Bahamas, Abaco Cays (great Sale Cay): 10-V-1953, Van Voast, AMNH Bahama Isls. Exped., Coll. E.B. Hayden \& G.B.Rabb leg. (um macho, AMNH); Cat Island (the Bight): 22-III-1953, Van Voast-AMNH Bahama Isls. Exped., Coll. Hayden, Giovannoli \& Rabb leg. (um macho, AMNH); Berry Island, Fraziers Hog Cay leg., 30-IV-1953 (um macho, AMNH).

\section{Tomosvaryella dissimilis Hardy, 1943}

Tomosvaryella dissimilis Hardy, 1943: 161. Figs 89a-e. - Aczél, 1948: 20 (distribuição). - Hardy, 1965 c (catálogo).

O material foi identificado por comparação com cinco parátipos de $T$. dissimilis provenientes do Snow Entomological Museum. Condições dos parátipos: boa.

Registros geográficos. E.U.A., México (novo registro).

Material examinado. MÉxico, Baja California Sur: Sierra La Laguna (1770-1850m), 01-IX-1977 (um macho, CAS); (3 Km E. La Burrera, 515m) 2-3-IX-1977, F. Fisher \& R. Westcott leg. (um macho, CAS); San Luis Potosí: El Bonito (7mi. S. of Ciudad Valles, el 300'), 19-XII-1970, P.H. \& M. Arnaud leg. (dois machos, CAS); 20-XII-1970 (sete machos, CAS; um macho, INPA); Tamazunchale (alt. 400'), 22-XII-1970 (um macho, CAS; dois machos, INPA).

Discussão. Espécie muito próxima de T. scopulata, difere pela forma do processo do trocanter posterior, espiniforme.

\section{Tomosvaryella galapagensis (Curran, 1934)}

Pipunculus galapagensis Curran, 1934: 152

Tomosvaryella galapagensis; Aczél, 1948: 25 (distribuição); 1952: 248 (catálogo). - Hardy, 1965b: 64 (citação): 1966: 8 (catálogo). - Ale-Rocha, 1992: 319, Figs 1-8 (redescrição).

Registros geográficos. Equador (Ilhas Galápagos), México (novo registro).

Espécimens examinados. MéxıCO, Baja California:Sierra San Pedro Martir (La Grulla el 6900 ft.), 13-VI-1953, P.H.Arnaud Jr. leg. (um macho, CAS); Baja California Norte: Sulphur mine south of San Felipe, 13-XI-1967, Don Patterson leg. (um macho, CAS); 1 mi. up canyon, 3m S. of Oakie Landing, 14-XI-1967 (um macho, CAS); Baja California Sur: Isla San Francisco (unnamed cove, S end coastal dunes), 1-IV-1974, John T. Doyen leg., Ex Malaise trap (um macho, INPA); Isla San Jose (1 mi S Punta Colorado), 8-9-IV-1974 (um macho, CAS). 


\section{Tomosvaryella lynchi (Shannon, 1927)}

Figs 14-20

Pipunculus lynchi Shannon, 1927: 38: Collin, 1931: 56 (citação).

Tomosvaryella lynchi; Aczél, 1948: 25 (distribuição); 1952: 248 (catálogo). - Hardy, 1953: 300, Figs 1-4 (redescrição); 1954: 56 (citação); 1965a: 236, Figs 15a-c (distribuição, breve descrição); 1965b: 64 (chave); 1966: 8 (catálogo).

Tomosvaryella tumida Hardy, 1940: 112, Figs 7a-f; 1943: 182, Figs 104a-c (descrição). - Aczél, 1948: 23 (distribuição); 1952: 248 (catálogo). - Hardy, 1965c (catálogo), syn.n.

Tomosvaryella lepidipes: Hardy, 1965b: 65 (identificação errônea).

Holótipo macho. Corpo: 2,5mm; asa: 2,8mm.

Redescrição. Cabeça: triângulo frontal com pruinosidade cinza-prateada, preto-fosco em vista frontal; triângulo ocelar curto; pós-crânio com pruinosidade cinza-prateada forte na metade inferior estendendo-se numa faixa estreita, mais diluída, ao longo da margem do olho até próximo o vértice; flagelo com ápice agudo; olhos contíguos por seis facetas. Tórax: escudo preto sub-brilhante com pruinosidade castanha, cerdas inconspícuas; escutelo preto-brilhante, cerdas marginais curtas. Pernas: pretas, exceto os ápices dos fêmures e tíbias, quarto basal das tíbias e tarsômeros basais amarelos, quinto tarsômero castanho; fêmur anterior com dois espinhos sub-basais ventrais curtos e fracos; trocanter posterior com processo como um pequeno monte (Fig. 14); cerdas da face posterior do fềmur posterior curtas; tarsos posteriores levemente alargados, primeiro tarsômero maior que os três seguintes juntos em comprimento. Asa: hialina, terceira seção costal igual a 1/2 da quarta, lobo anal médio. Abdome (tradução da descrição original): "preto-brilhante com pruinosidade castanha esparsa dorsal e cinza-prateada nas laterais; cerdas distintas, eretas e esparsas". Terminália: sintergoesternito $8 \mathrm{em}$ vista dorsal um tanto arredondado no ápice, cerca de $3 / 4$ do comprimento do tergito 5 , área membranosa sub-apical, fenda longitudinal extendendo-se do ápice até a base (Figs 15, 16); surstilos robustos (Figs 17, 18); ramificações do edeago curtas, parâmero com pequeno espinho dorsal (Fig. 19); apódema ejaculador como na figura 20.

Fêmea. Descrita por HARDY (1940) como T. tumida.

Registros geográficos. E.U.A., México (novo registro), Costa Rica (novo registro), Brasil, Argentina.

Material tipo examinado. [ARgentina], Tafí Viejo, Tuc[cumán], 14.III. [19]27, R.C. Shannon (Cotype (sic) (Holótipo macho $\mathrm{n}^{\circ} 40820$, USNM). T. lynchi); [U.S.A.], Belle Glade, Florida, 18.VII.[19]39, D.E.Hardy (Holótipo macho, SMEK. T. tumida). Condições dos holótipos: T. lynchi - pernas posteriores e abdome em microtúbulo com glicerina, asa esquerda montada em microlâmina; T. tumida - antena esquerda, perna média direita, tarso posterior direito e tibia posterior esquerda perdidos.

Outros espécimens examinados. MÉxico, Manzamitla: Pine forest 7 miles S., XII. 1948, H.B.Leech leg. (um macho, CAS); San Luis Potosi: El Bonito (7 mi. S of Ciudad Valles, el. 300), 20-XII-1970, P.H. \& M. Arnaud leg. (um macho, CAS); 21-XII-1970 (um macho, CAS); Jalisco: Puerto Vallarta, 1-I-1971, sea 


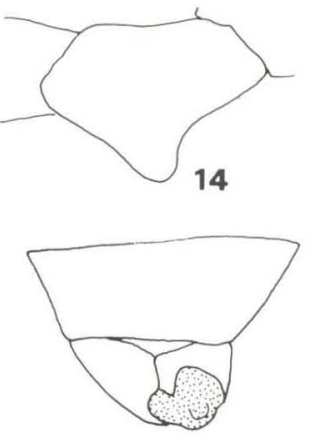

15

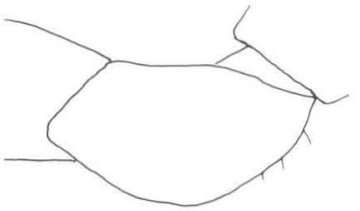

21
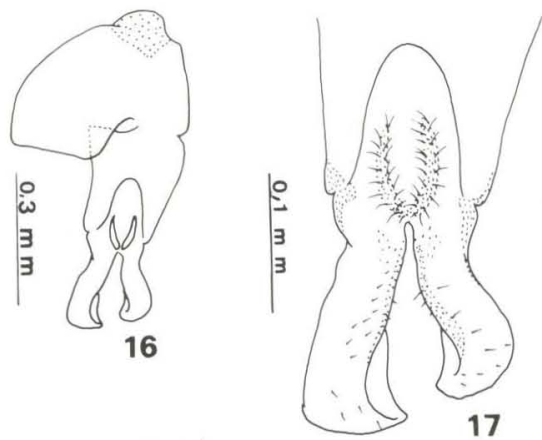

17
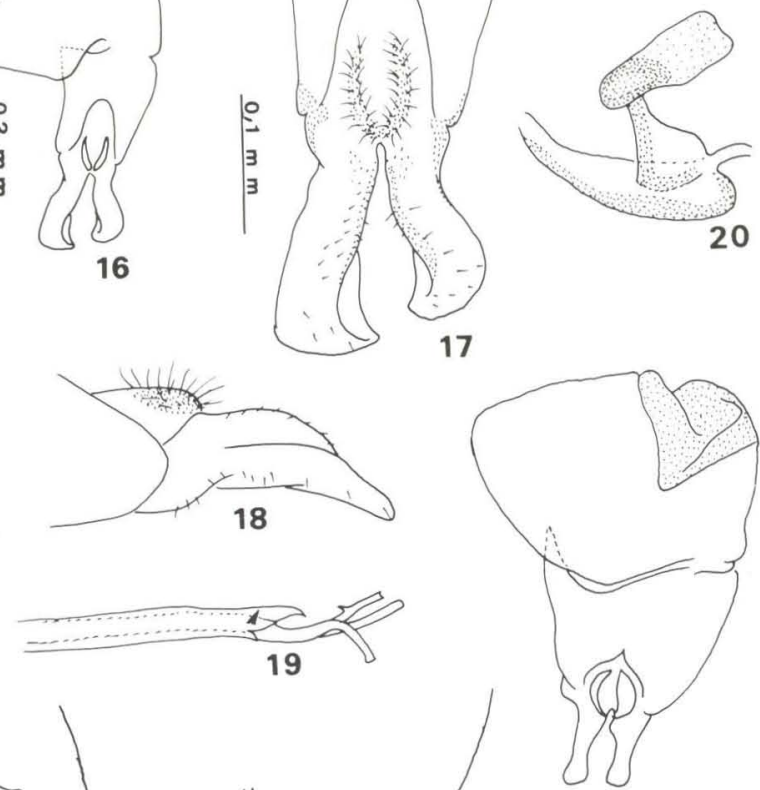

23

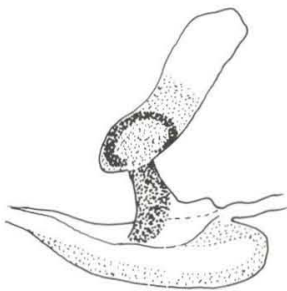

28
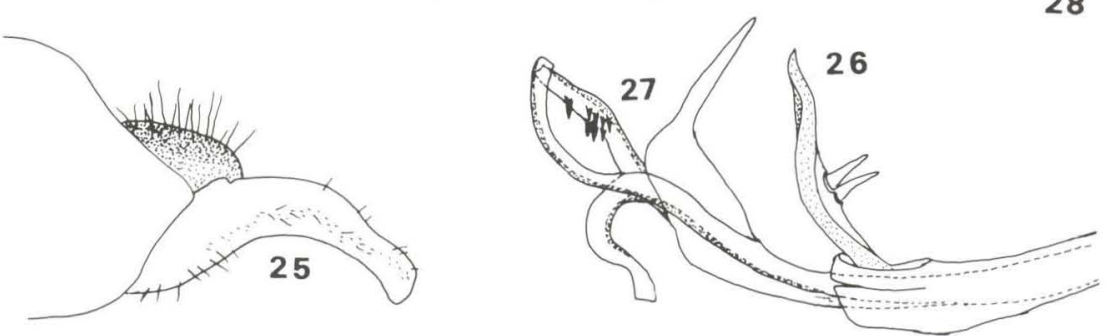

Figs 14-28. (14-20) Tomosvaryella lynchi, holótipo macho. (14) Trocanter posterior; (15) terminália dorsal; (16) terminália ventral; (17) surstilos; (18) surstilo direito, lateral; (19) parâmero e edeago; (20) apódema ejaculador. (21-28) Tomosvaryella membranacea, sp.n. holótipo macho. (21) Trocanter posterior; (22) terminália dorsal; (23) terminália ventra! (24) surstilos; (25) surstilo direito, lateral; (26) parâmero; (27) edeago; (28) apódema ejaculador. Figuras $14,17-21,24-26 ; 15,22 ; 16,23$ na mesma escala. 
level (dois machos, CAS); Yucatan: Itzima, 05-IX-1964, J.C. \& D. Pallister leg. (dois machos, CAS); 11-IX-1964 (dois machos, CAS); 13-IX-1964 (dois machos, CAS); Baja California Sur: 3km E. La Burrera, 515m, 2-3-IX-1977, E. Fisher \& R. Westcott leg. (um macho, CAS). Costa RicA, Barranca: (nr. Puntarenas), 25-VIII-1954, E.S. Ross leg. (um macho, CAS).

Variações. O processo ventral do trocanter posterior se apresenta em forma de monte com o ápice arredondado ou afilado.

\section{Tomosvaryella membranacea, sp.n.}

Figs 21-28

Holótipo macho. corpo 3,4mm; asa 2,95mm.

Cabeça. Triângulo frontal com pruinosidade cinza-prateada; triângulo ocelar curto; pós-crânio preto com pruinosidade cinza-prateada na metade inferior, extendendo-se até próximo o vértice numa faixa estreita, margeando o olho; ápice do flagelo agudo; olhos contíguos por cinco a seis facetas.

Tórax. Escudo preto com pruinosidade dorsal castanha, mais pálida na região pré-sutural, cerdas inconspícuas; escutelo com pruinosidade cinza-prateada em vista posterior, cerdas marginais curtas.

Pernas. Pretas, exceto os ápices dos fêmures e tíbias, terço basal das tíbias e tarsômeros basais amarelos, quinto tarsômero castanho; fêmur anterior com dois espinhos sub-basais ventrais conspícuos; trocanter posterior com processo ventral arredondado (Fig. 21); cerdas alongadas e delgadas na face posterior do fêmur posterior; tarso posterior fracamente alargado; primeiro tarsômero igual, em comprimento, aos três seguintes combinados. Asa: hialina; terceira seção costal cerca de 1/3 da quarta; lobo anal largo. Abdome: preto, brilhante, pruinosidade dorsal castanha esparsa, pruinosidade cinza-prateada em todo o tergito 1 e nas laterais dos tergitos 4 e 5 ; robusto, lados quase paralelos; cerdas esparsas e fracas, levemente maiores no tergito 5 . Terminália: sintergoesternito 8 cerca de $2 / 3$ do tergito 5, área membranosa larga (Figs 22, 23); surstilos assimétricos, estreitos, truncados no ápice (Figs 24, 25); parâmero longo com dois espinhos dorsais fortes e iguais (Fig. 26); edeago envolto por uma membrana larga, ramificações alongadas, ramo dorsal com área espinhosa (Fig. 27); bulbo do apódema ẹjaculador longo (Fig. 28).

Fêmea. Desconhecida.

Registro geográfico. México.

Material tipo examinado. MÉX[ICO]: Sonora, Álamos, 26.II.1963, P.H. Arnaud Jr. (Holótipo macho, CAS). Parátipo: MÉxICO, Jalisco, Puerto Vallarta, 31.XII.1970, P.H. \& M.Arnaud, sea level (um macho, CAS). Condição do holótipo: abdome e perna posterior esquerda em microtúbulo com glicerina.

Etimologia. Do latim membrana, refere-se à membrana que cobre o edeago. 


\section{Tomosvaryella mexicanensis, sp.n.}

Figs 29-35

Holótipo macho. Corpo 3,6mm; asa 3,3mm.

Cabeça. Triângulo frontal com pruinosidade dourado-pálida; triângulo ocelar do mesmo comprimento da área contígua dos olhos; pós-crânio preto, brilhante, pruinosidade cinza-prateada na metade inferior; ápice do flagelo agudo; olhos contíguos por oito a nove facetas. Tórax: largo; escudo preto-brilhante, pruinosidade dorsal castanho-avermelhada, cerdas inconspícuas; escutelo pretobrilhante, pruinosidade castanha pálida, quase prateada em vista anterior, cerdas marginais um pouco maiores que as do escudo. Pernas: pretas, exceto os ápices dos fêmures e quinto basal das tíbias castanho-claras, tarsos castanho-escuros; fêmur anterior com dois espinhos sub-basais ventrais; trocanter posterior com processo ventral afilado apicalmente (Fig. 29); cerdas longas e finas na face posterior do fềmur posterior; fêmur e tíbia posteriores mais robustos que os outros; tarsos posteriores levemente dilatados, primeiro tarsômero igual aos três seguintes combinados. Asa: hialina; terceira seção costal igual a 1/3 da quarta; lobo anal largo. Abdome: oval, robusto, preto-brilhante, pruinosidade cinza-prateada nas laterais dos tergito 1 e 5, pruinosidade dorsal castanha, esparsa; cerdas pretas, esparsas, curtas, levemente maiores no tergito 5. Terminália: área membranosa mediana, estreita, estendendo-se do ápice à base do sintergoesternito 8 (Figs 30, 31); surstilos longos (Figs 32, 33); parâmero com espinho dorsal, ramificação dorsal do edeago com uma fileira longitudinal de espinhos curtos (Fig. 34); apódema ejaculador como na figura 35.

Fêmea. Desconhecida.

Registro geográfico. México.

Material tipo examinado. México, San Luis Potosí, El Bonito, $7 \mathrm{mi}$.S of Ciudad Valles, el 300', 20-XII-1970, P.H.\& M.Arnaud (Holótipo macho; um parátipo macho, CAS). Condição do holótipo: perna posterior direita e abdome em microtúbulo com glicerina; asa esquerda montada em microlâmina.

Etimologia. O nome específico refere-se ao país de origem do material.

Tomosvaryella polita (Williston, 1896)

Pipunculus politus Williston, 1896: 351, pl. XI. Fig. 88 (descrição breve). - Cresson, 1911: 314 (citaçâo).

Tomosvaryella politus; Hardy, 1943: 146 (distribuição).

Tomosvaryella polita: Aczél, 1948: 26 (distribuição); 1952: 248 (catálogo). - Hardy, 1966: 8 (catálogo).

Espécie não reconhecida face à sua breve descrição. O tipo está provavelmente perdido.

Registro geográfico. São Vincente (Antilhas). 


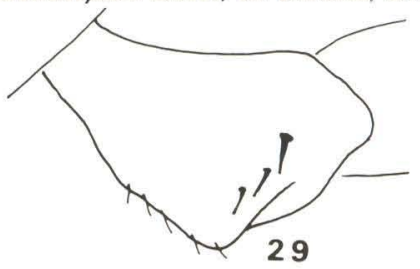

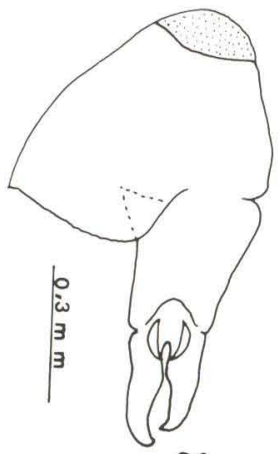

31

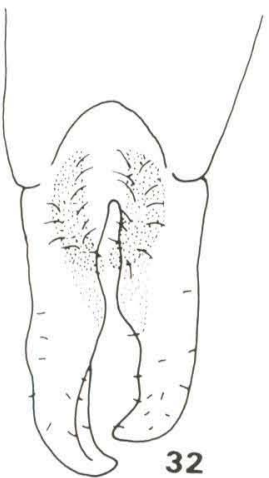

32

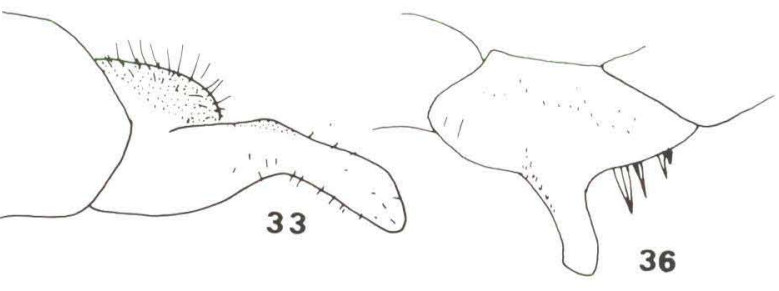

35
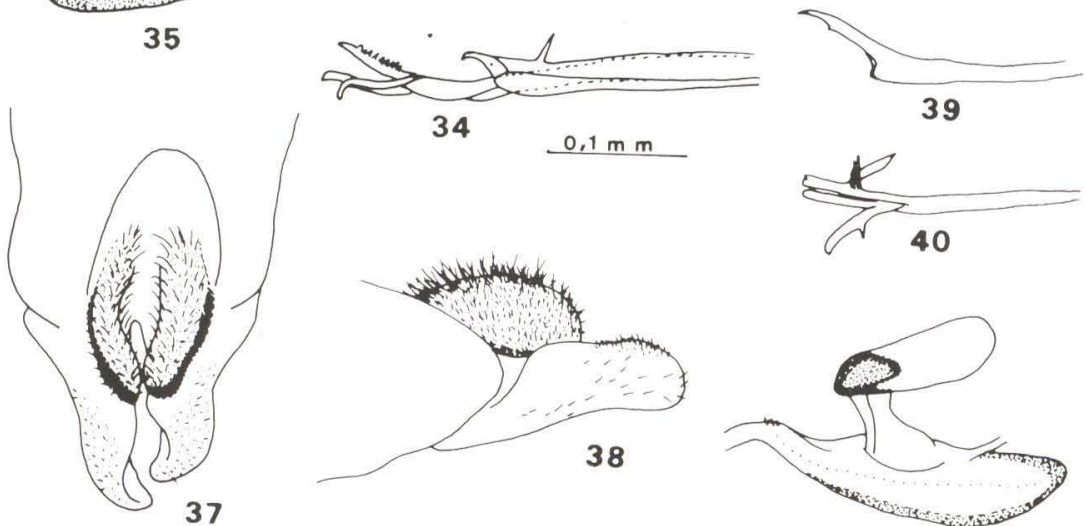

39
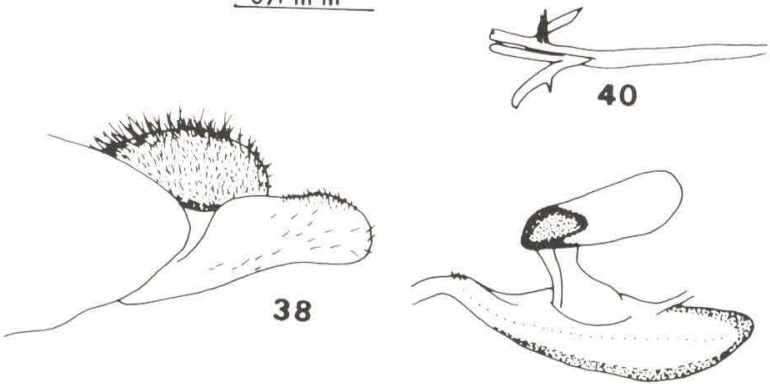

41

Figs 29-41. (29-35) Tomosvaryells mexicanensis, sp.n., holótipo macho. (29) Trocanter posterior; (30) terminália dorsal; (31) terminália ventral; (32) surstilos; (33) surstilo direito, lateral; (34) parâmero e edeago; (35) apódema ejaculador. (36-41) Tomosvaryella sachtlebeni, holótipo macho. (36) Trocanter posterior; (37) surstilos; (38) surstilo esquerdo, lateral; (39) parâmero; (40) edeago; (41) apódema ejaculador. Figuras 29, 32-41 na mesma escala.

\section{Tomosvaryella sachtlebeni (Aczél, 1940)}

Figs 36-41

Pipunculus sachtlebeni Aczél, 1940: 152

Tomosvaryella sachtlebeni Hardy, 1943: 173, Figs 97a-e (redescrição). - Aczél, 1948: 22, 24 (distribuição). - Hardy, 1965a: 856 (catálogo). 
Holótipo macho. Corpo 3,0mm; asa 3,2mm.

Corpo preto, brilhante, escudo com pruinosidade dorsal castanha densa e cinza-prateada na região pré-sutural, cerdas dorsais do escudo e escutelo curtas, terceira seção costal cerca de $2 / 3$ da quarta, lobo anal médio, trocanter posterior com processo espiniforme (Fig. 36), surstilos semi-simétricos com ápices afilados e côncavos na face interna (Figs 37, 38), cercos longos, protuberantes, com pilosidade castanho-dourada, parâmero simples (Fig. 39), edeago com ramificações curtas, ramo dorsal do edeago com dois espinhos curtos e outro longo e forte (Fig. 40), apódema ejaculador com saco espermático dilatado (Fig. 41).

Fêmea. Descrita por HaRDY (1943).

Registros geográficos. E.U.A., México (novo registro).

Material tipo examinado. [E.U.A.], Falls Church, Va [Virginia] (Holótipo macho, MCZ). Condição do holótipo: perna posterior esquerda perdida, abdome em microtúbulo com glicerina.

Outros espécimens examinados. MÉXICO, Sonora: Álamos, 04-I-1971, P.H. \& M. Arnaud leg. (um macho, CAS); Baja California Sur: Isla San José (1 mi. S. Punta Colorado), 8-9-IV-1974, John T. Doyen leg. (um macho, CAS); San Luis Potosí: El Bonito (7mi. S. of Ciudad Valles, el 300'), 19-XII-1970, P.H. \& M. Arnaud leg. (um macho, CAS; um macho, INPA); 20-XII-1970 (dois machos, CAS); 21-XII-1970 (dois machos, CAS).

Variação. Os espécimens do México apresentam o fêmur, a tíbia e o tarso posterior fortemente dilatados.

\section{Tomosvaryella scopulata Hardy, 1963}

Figs $42-50$

Tomosvaryella scopulata Hardy, 1963: 262. Figs 1i-1; 1965b: 64. Figs 24f.g (chave); 1966: 8 (catálogo). - Scarbrough \& Knutson, 1989: 526, Figs 4a-d (chave).

Holótipo macho. Corpo 2,8mm; asa 3,0mm.

Corpo preto, tórax com cerdas curtas e pruinosidade dorsal castanha, mais pálida na região pré-sutural, trocanter posterior com processo em forma de monte (Fig. 42), face posterior do fềmur posterior com cerdas delgadas e alongadas, terminália estreita (Fig. 43), surstilos robustos com projeção dorsal longitudinal cerdosa e truncados apicalmente (Figs 45-47), parâmero simples (Fig. 48), ramificações do edeago curtas (Fig. 49), bulbo do apódema ejaculador alargado no ápice (Fig. 50).

Fêmea. Desconhecida.

Registros geográficos. Colômbia, Dominica, México (novo registro), Cuba (novo registro).

Material tipo examinado. Colombia, Palmira (Valle), 6.VI.1958 (G. Bravo) (Holótipo macho, CAS). Condição do holótipo: pernas posteriores e abdome em microtúbulo com glicerina; asa esquerda montada em microlâmina; flagelo e arista esquerda perdidos.

Outros espécimens examinados. MÉXICO: San Luis Potosí: El Bonito (7mi. 
Tomosvaryella Aczél, do México, América ...
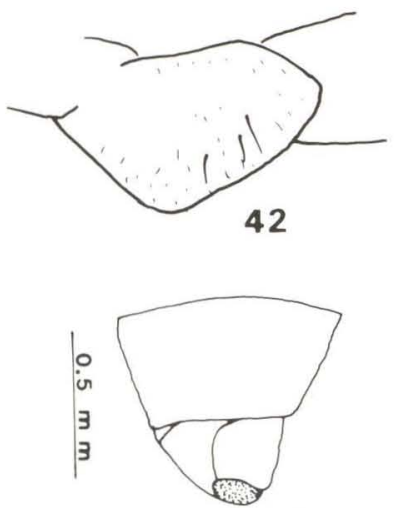

43

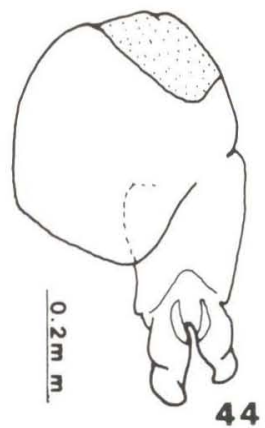

44

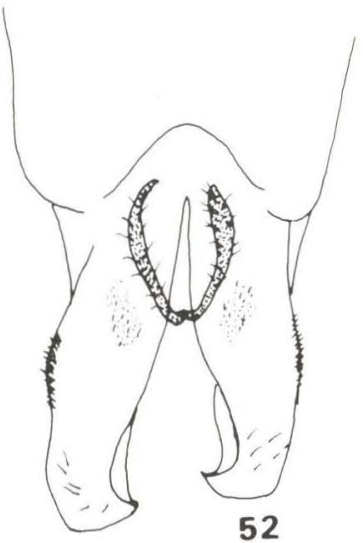

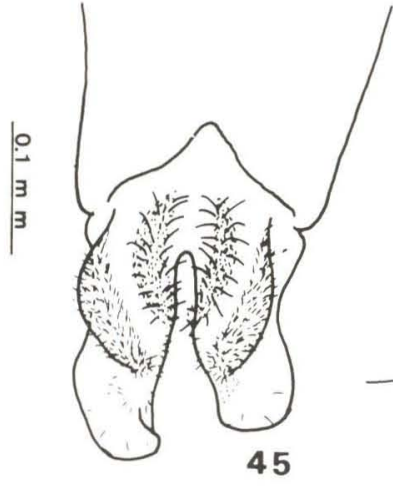

45
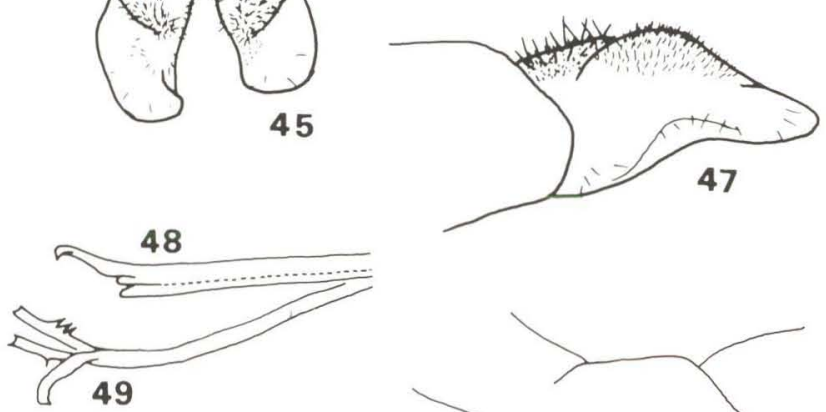

46

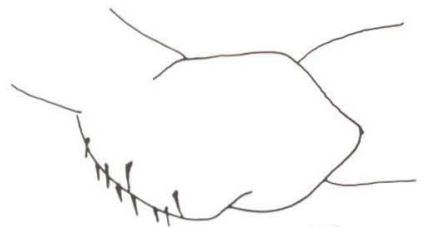

51

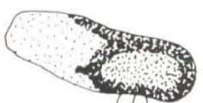

50
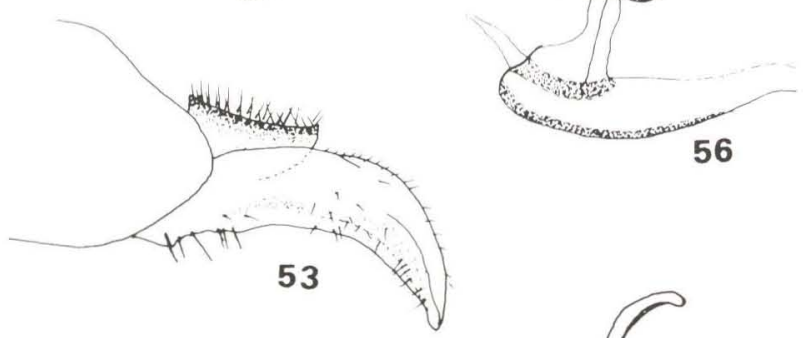

56

Figs 42-56. (42-50) Tomosvaryella scopulata, holótipo macho. (42) Trocanter posterior; (43) terminália dorsal; (44) terminália ventral; (45) surstilos; (46) surstilo esquerdo, lateral; (47) surstilo direito, lateral; (48) parâmero; (49) edeago; (50) apódema ejaculador. (51-56) Tomosvaryella similis, holótipo macho (exceto Fig. 51). (51) Trocanter posterior; (52) surstilos; (53) surstilo direito, lateral; (54) parâmero; (55) edeago; (56) apódema ejaculador. Figuras $42,45-56$ na mesma escala. 
S. of Ciudad Valles, el. 300') sic, 19-XII-1970, P.H. \& M. Arnaud (sete machos, CAS); 20-XII-1970 (14 machos, CAS; dois machos, INPA); 21-XII-1970 (10 machos, CAS; um macho, INPA); Tamazunchale (alt. 400') sic, 22-XII-1970 (dois machos, CAS). CuBA, Santiago de Cuba: 02-X-1913 (um macho, AMNH).

Observação. As terminálias do holótipo e dos espécimens do México e Cuba são idênticas, diferem, porém, das figuras de Hardy (1963 e 1965b).

Discussão. Espécie muito próxima de T. dissimilis, difere pelo processo do trocanter posterior em forma de monte.

\section{Tomosvaryella similis (Hough, 1899)}

\section{Figs 51-56}

Pipunculus similis Hough, 1899: 84.

Tomosvaryella similis; Hardy, 1943: 174. Figs 98a-h: Aczél, 1948: 22 (distribuição). - Hardy, 1965c: 856 (catálogo).

Holótipo macho. Corpo 3,8mm; asa 3,0mm.

Pós-crânio totalmente coberto com pruinosidade cinza-prateada forte, corpo sub-brilhante, robusto, pruinosidade cinza-prateada misturada com pruinosidade castanha no escudo, cerdas torácicas alongadas, pernas pruinosas exceto a face posterior do fêmur posterior, trocanter posterior abaulado ventralmente, com cerdas ventrais fortes (Fig. 51); surstilos grandes, semi-simétricos, com ápices truncados e face dorsal convexa (Figs 52, 53), ápice do parâmero curto (Fig. 54), ramificações do edeago longas (Fig. 55), apódema ejaculador como na figura 56.

Registros geográficos. E.U.A., México (novo registro), Bahamas (novo registro).

Material tipo examinado. [U.S.A], Tifton, Ga [Georgia], Nov' [18]96 (Holótipo macho, FMNH). Condição do holótipo: abdome em microtúbulo com glicerina, perna posterior direita e asa direita perdidos.

Outros espécimens examinados. MÉxico, Baja California: Sierra San Pedro Mártir (La Grulla, el 6900 ft.), 13-VI-1953, P.H. Arnaud Jr. leg. (um macho, CAS); San Luis Potosí: El Bonito (7 mi.S. of Ciudad Valles), 20-XII-1970, P.H. \& M. Arnaud leg. (um macho, CAS); Tamazunchale, 22-XII-1970 (três machos, CAS; um macho, INPA); Sinaloa: $80 \mathrm{Km}$ east of Mazatlan, 1850m, 23-IV-1974, Ernest Anderson leg. (um macho, CAS); Baja California Norte: San José (Meling Ranch), 03-VII-1968, Don Patterson leg. (um macho, CAS); Bahamas, Abaco Cays: Elbow Cay Hope Town, 04-V-1953, Van Voast-AMNH, Bahama Isl. Exped. coll. E.B.Hayden leg. (um macho, AMNH).

Observações. Durante o trabalho, foram examinados três parátipos de Tomosvaryella agnesea Hardy. Baseado na análise da morfologia externa e genitália, constatou-se tratar-se de $T$. similis. O holótipo de $T$. agnesea não foi estudado, mas, provavelmente, trata-se de um sinônimo de T. similis. A figura da terminália atribuída a T. similis, apresentada por HARDY (1943), não coincide com a figura do holótipo de $T$. similis apresentada neste trabalho. 


\section{Tomosvaryella sonorensis (Cole, 1923)}

Figs 57-64

Pipunculus sonorensis Cole, 1923: 466, Fig. 9.

Tomosvaryella sonorensis; Hardy, 1943: 176, pl.17. Fig. 99a (transcrição da descrição original). Aczél, 1948: 26 (distribuição); 1952: 248 (catálogo). - Hardy, 1965b: 64 (citação); 1966: 8 (catálogo). - Cole, 1969: 301 (distribuição).

Holótipo macho. Corpo $3,5 \mathrm{~mm}$; asa $3,0 \mathrm{~mm}$.

Redescrição. Cabeça: triângulo frontal com forte pruinosidade cinzaprateada em vista dorsal, preto-fosco em vista frontal; triângulo ocelar curto; pós-crânio castanho-escuro, pruinosidade cinza-prateada na metade inferior; ápice do flagelo agudo; olhos contíguos por quatro a cinco facetas. Tórax: escudo e escutelo pretos, sub-brilhantes, cerdas curtas, pruinosidade dorsal castanha exceto na área pré-sutural do escudo; escutelo com pruinosidade cinza-prateada. Pernas: castanho-escuras exceto os ápices dos fêmures e tíbias, 1/3 basal das tíbias amarelos, tarsos castanho-claros; espinhos sub-basais do fềmur anterior não observados; trocanter posterior com processo ventral quadrado (Fig. 57); cerdas delgadas e curtas na face posterior do fêmur posterior; tarso posterior discretamente dilatado. Asa: hialina; terceira seção costal igual a 1/2 da quarta; lobo anal largo. Abdome: preto com fina pruinosidade cinza-prateada; cerdas fracas e esparsas. Terminália: sintergoesternito 8 tão longo quanto o tergito 5 (Figs 58 , 59); surstilos estreitando-se em direção ao ápice, cercos subdivididos em quatro lóbulos grandemente desenvolvidos (Figs 60, 61); parâmero simples (Fig. 62), ramificações do edeago curtas (Fig. 63); apódema ejaculador como na fïgura 64.

Fêmea. Desconhecida.

Registro geográfico. México.

Material tipo examinado. MÉx[ICO], Sonora, Tepoca Bay, 25.IX.1921, E.P. Van Duzee (Holótipo macho, CAS). Condição do holótipo: flagelo esquerdo perdido; perna posterior esquerda e terminália em microtúbulo com glicerina; asa esquerda montada em microlâmina.

\section{Tomosvaryella spangleri Scarbrough \& Knutson, 1989}

Figs $65-70$

Tomosvaryella spangleri Scarbrough \& Knutson, 1989: 526, 530, Figs 6-10.

Holótipo macho. Corpo 2,4mm; asa 2,5mm.

Corpo castanho-escuro a preto, sub-brilhante; escudo e escutelo com pruinosidade castanho-avermelhada; cerdas torácicas curtas; trocanter posterior com processo mediano ventral em forma de monte, afilado e piloso apicalmente (Fig. 65); face posterior do fêmur posterior com cerdas curtas; surtilos simétricos, largos e angulosos na base, ápices em pinça (Figs 66, 67); ápice do parâmero longo com pequeno espinho dorsal (Fig. 68); edeago com ramificações médias (Fig. 69); apódema ejaculador como na figura 70.

Fêmea. Descrita adequadamente junto com o macho.

Registro geográfico. Dominica. 

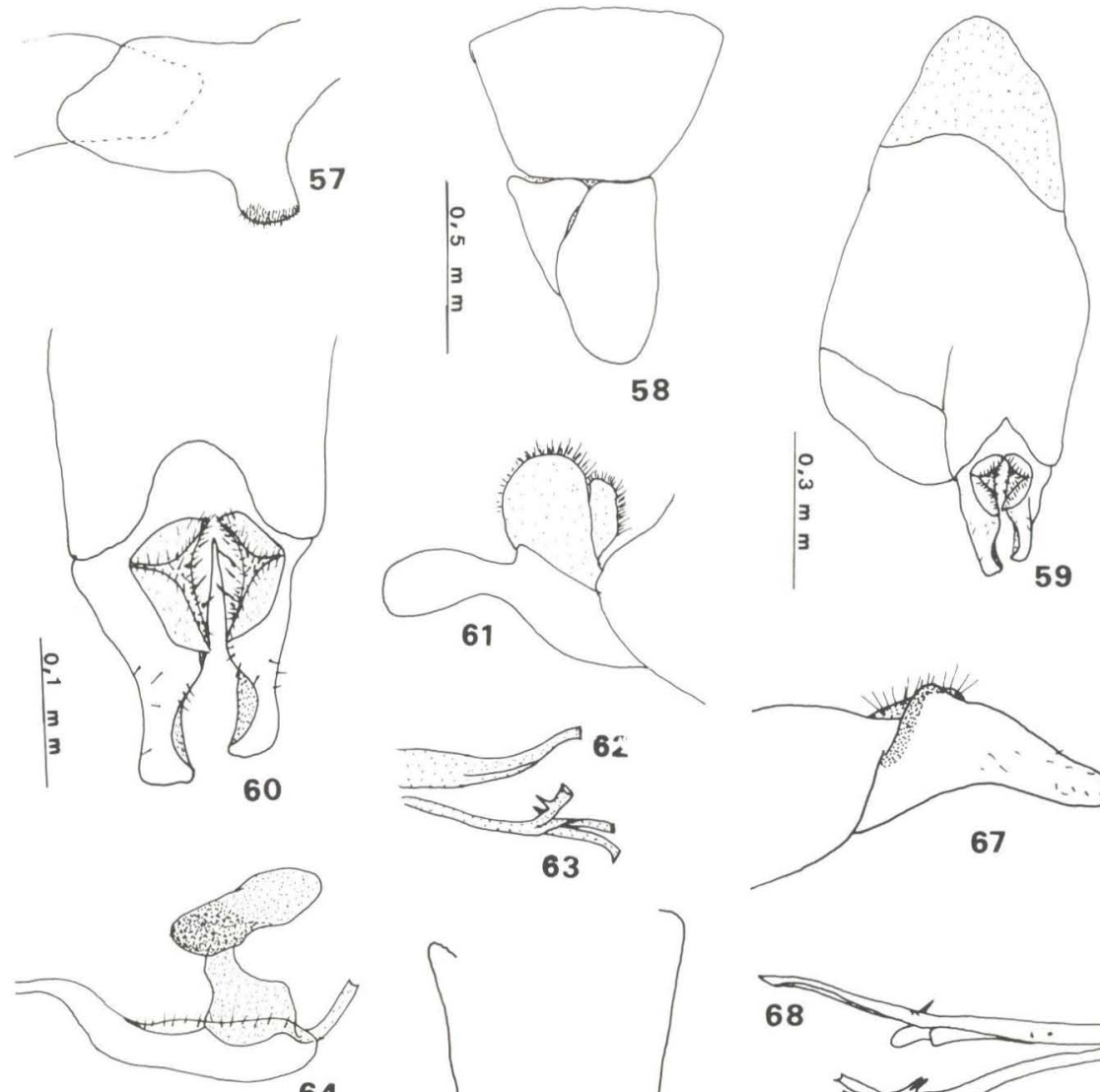

64
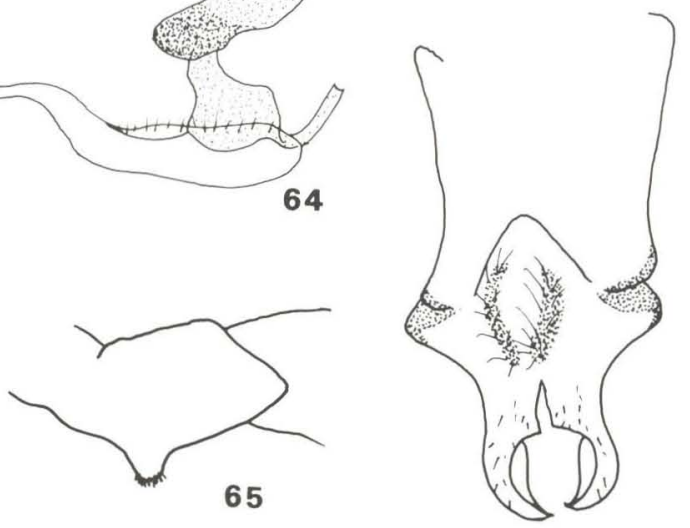

66
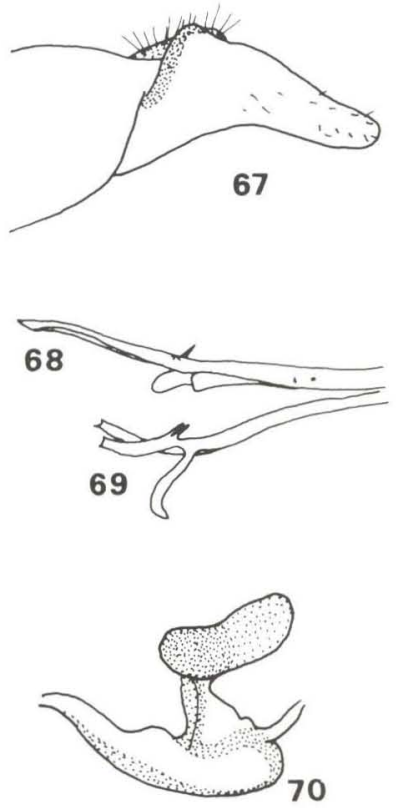

Figs 57-70. (57-64) Tomosvaryella sonorensis, holótipo macho. (57) Trocanter posterior; (58) terminália dorsal; (59) terminália ventral; (60) surstilos; (61) surstilo esquerdo, lateral; (62) parâmero; (63) edeago; (64) apódema ejaculador. (65-70) Tomosvaryella spangleri, holótipo macho. (65) Trocanter posterior; (66) surstilos; (67) surstilo direito, lateral; (68) parâmero; (69) edeago; (70) apódema ejaculador. Figuras 57, 60-70 na mesma escala.

Material tipo examinado. DominiCA, Fond Colet, 5-9.X.1964, P.J. Spangler (Holótipo macho, USNM); PUERTO RICO, Ensenada Honda, 20. VII. [19]42, C.E. Pederson (Parátipo macho, USNM). Condição do holótipo: abdome em microtúbulo com glicerina. 


\section{Tomosvaryella subvirescens (Loew)}

Pipunculus subvirescens Loew, 1872: 87.

Tomosvaryella sthvirescens; Hardy, 1943: 178, pl 17, Figs 101a-e. - Ale-Rocha (no prelo) (redesc rição).

Espécie facilmente reconhecida pelo trocanter posterior com processo ventral curto, achatado apicalmente; sintergoestenito 8 simétrico, sub-hemisférico; edeago com ramos longos e enrolados; bulbo do apódema ejaculador grande e arredondado apicalmente e saco espermático reduzido; abdome clavado em vista lateral.

ALE-Rocha (no prelo) redescreve a espécie com figuras da terminália e trocanter posterior do holótipo.

Registros geográficos: espécie amplamente distribuída nas regiões Paleártica, Etiópica, Oriental, Australiana, Neártica e Neotropical, sendo estes os primeiros registros para o México, Bahamas e Belize.

Espécimens examinados. MÉxICo, San Luis Potosí: Tamazunchale, 23-XI-1946, F.E. Skinner leg. (um macho, CAS); El Bonito (7 mi. S of Ciudad Valles, el. 300') sic, 19-XII-1970, P.H. \& M. Arnaud leg. (um macho, CAS); 20-XII-1970 (um macho, CAS); 21-XII-1970 (um macho, CAS). BAHAMAS, Abaco Cays: 04-V-1953, Bahama Isls. Exped., Coll. E.B. Hayden leg. (um macho, AMNH). Belize, Cayo: $1 \mathrm{~m} \mathrm{~S}$ of San Ignacio, 22-27-VII-1978, P.S. Broomfield, leg. (um macho, BMNH).

\section{Tomosvaryella tuberculata Hardy, 1948}

Figs $71-76$

Tomosvaryella tuberculata Hardy, 1948: 11, Figs 7a-d. - Aczél, 1952: 249 (catálogo). - Hardy, 1965b: 64 (citação): 1966: 8 (catálogo). - Dalmau \& Ávila. 1983: 62 (lista). - Scarbrough \& Knutson. 1989: 526. 528, Fig. 5 (chave, descrição fềmea).

Holótipo macho. Corpo 2,8mm; asa 2,5mm.

Redescrição. Cabeça: triângulo frontal com pruinosidade cinza-prateada; triângulo ocelar preto-brilhante, do mesmo comprimento da porção contígua dos olhos; pós-crânio preto com pruinosidade cinza-prateada na metade inferior; peças bucais amarelas; antena castanha com pruinosidade amarelo-pálida, flagelo acuminado com margens mais claras; pedicelo com uma cerda inferiormente; olhos contíguos por oito a nove facetas. Tórax: escudo preto, sub-brihante com pruinosidade castanha, cerdas curtas; escutelo preto-brilhante com cerdas marginais curtas; notopleura com pruinosidade cinza-prateada; mesopleura mais clara que o escudo com pruinosidade cinza-prateada esparsa. Pernas: pretas, exceto o ápice do fêmur, 1/3 hasal e ápice das tíbias anterior e médias e tarsômeros basais amarelos; quinto tarsômero castanho; tíbia posterior com área apical amarela mais larga que nas outras; pernas com tina pruinosidade cinza-prateada exceto a face posterior do fêmur posterior; fêmur anterior com dois espinhos sub-basais ventrais; trocanter posterior com processo espiniforme, longo, robusto e curvado para a base, com ápice arredondado e um par de pequenas cerdas anteriores (Fig. 71); 

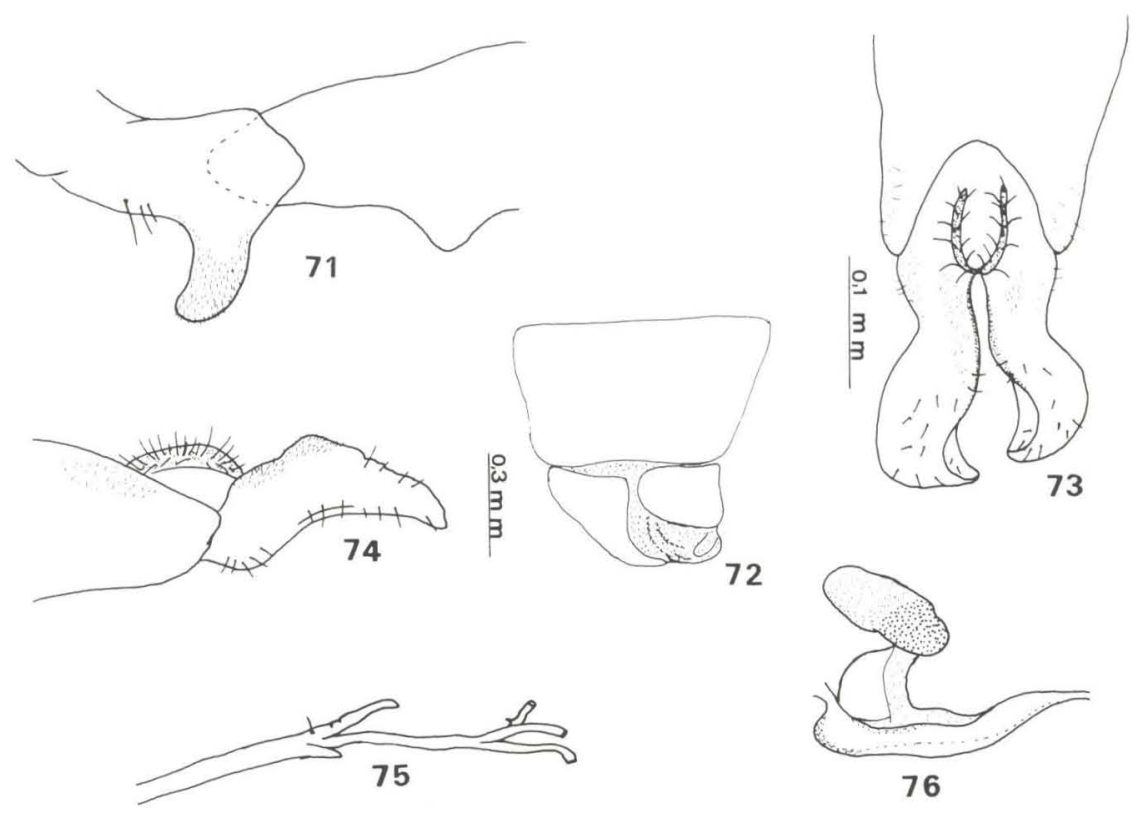

Figs 71-76. Tomosvaryella tuberculata, holótipo macho. (71) Trocanter posterior; (72) terminália dorsal; (73) surstilos; (74) surstilo direito, lateral; (75) parâmero e edeago; (76) apódema ejaculador. Figuras 71, 73-76 na mesma escala.

fêmur posterior moderadamente dilatado, a face posterior com cerdas curtas, um distinto tubérculo na base; tarso posterior mais alargado que os demais. Asa: suavemente acastanhada; terceira seção costal cerca de $1 / 2$ da quarta; r-m localizada um pouco antes do meio da célula discal. Abdome: preto, alongado e estreitado, com pruinosidade castanha, pruinosidade cinza-prateada nas laterais do tergito 5; cerdas fracas e esparsas. Terminália: sintergoesternito 8 cerca de $3 / 4$ do tergito 5 (Fig. 72); surstilos robustos com ápices curvados para dentro (Figs 73, 74); parâmero com ápice curto e um espinho dorsal, edeago com ramificações curtas (Fig. 75); apódema ejaculador como na figura 76.

Fêmea. Descrita por SCARBRough \& KNUTSON (1989).

Registros geográficos. México (novo registro), Bahamas, Cuba, Dominica, Haiti, Jamaica, Costa Rica (novo registro).

Material tipo examinado. CuBA, Soledad near Cienfuegos, 6.vii.[19]20, N.Banks (Holótipo macho $\mathrm{n}^{\circ}$ 27705, MCZ.). Condição do holótipo: perna posterior esquerda e terminália em microtúbulo com glicerina, asa direita montada em microlâmina.

Outros espécimens examinados. MÉXICO, San Luis Potosí: El Bonito (7 mi. S of Ciudad Valles, el.300'), 20-XII-1970, P.H. \& M. Arnaud leg. (quatro machos, CAS); 21-XII-1970 (um macho, CAS); Tamazunchale: alt. 400', 22-XII1970 (um macho, CAS); Jalisco: Puerto Vallarta, 31-XII-1970 (11 machos e quatro fêmeas, CAS; um macho, INPA); 1-I-1971, sea level (12 machos e seis 
fềmeas, CAS). JamaicA, Kingston: nr. Mt. Royal Hotel, 24-IV-1959, sweeping, Tom B. Sexton, Jr. leg. (um macho, CAS). Costa RICA, Cartago: Turrialba (2000'), 14-VII-1965, H.G. Real leg. (um macho, CAS).

Variação. O tubérculo na base do fêmur posterior apresenta-se pouco desenvolvido em alguns espécimens.

Discussão. Espécie muito próxima de $T$. appendipes. Difere por ter os tarsos posteriores estreitos e o tubérculo sub-basal do fêmur posterior não desenvolvido como em $T$. appendipes.

\section{FÊMEAS NÃO IDENTIFICADAS}

As associações das fêmeas com machos no gênero Tomosvaryella são muito difíceis e não há certeza quando esta associação é feita de material coletado por armadilhas, quando várias espécies ocorrem no mesmo local.

Os seguintes espécimens fềmeas não puderam ser associadas aos machos, permanecendo sem identificação: MÉXICO, Baja California Norte: Sulphur mine (South of San Felipe), 13-XI-1967, Don Patterson leg. (uma fềmea, CAS); Sierra Juarez (16 mi. E. of La Rumorosa in Canyon S. of Higway 2 ca. 1500'), 8-IV-1971, Herman G. Real leg. (uma fêmea, CAS); Baja California: Sierra San Pedro Mártir (La Zanga, el 6800 ft), 13-VI-1953, P.H. Arnaud Jr. leg. (uma fềmea, CAS); 16-VI-1953 (uma fềmea, CAS); Baja California Sur: Isla San José (Bahia Amortajada), 9-IV-1974, John T. Doyen leg. (uma fềmea, CAS); 1 mi S. Punta Colorado, 8-9-IV-1974 (uma fềmea, CAS); 3km E. La Burrera, $515 \mathrm{~m}$, 2-3-IX-1977, E. Fisher, R. Westcott leg. (uma fêmea, CAS); Sonora: 134 road km, South Soyota, 15-II-1963 (uma fềmea, CAS); Alamos, 27-II-1963, P.H. Arnaud Jr. leg. (uma fêmea, CAS); 5-I-1971, P.H. e M. Arnaud leg. (três fềmeas, CAS); Sinaloa: El Alamo (1500'), 27-IX-1970, D.E. Bredlove leg. (uma fêmea, CAS); Nuevo Leon: 2mi S. Montemorelos (1000'), 21-IX-1975 (91 fêmeas, CAS); Zacatecas: Laguna Balderama (25mi W Fresnillo, $7960 \mathrm{ft}$ ), 23-VI-1954, R. Brewer leg. (uma fêmea, CAS); S.E. Citlaltepetl Fortin, 03-VII-1964, el 3000, L.W. Swan (uma fềmea, CAS); Pine forest (7 miles S. Manzamitla), 01-XII-1948 (uma fềmea, CAS); San Luis Potosí: El Bonito (7mi S. of Ciudad Valles, el 300'), 19-XII-1970, P.H. \& M. Arnaud leg. (nove fềmeas, CAS); 20-XII-1970 (33 fềmeas, CAS); 21-XII-1970, (nove fềmeas, CAS); 22-XII-1970 (seis fềmeas, CAS); Jalisco: Puerto Vallarta, 1-I-1971, P.H \& M. Arnaud leg., sea level (três fềmeas, CAS); 31-XII-1970 (duas fềmeas, CAS); Guadalajara, 27-VI-1969, S.G. Williams leg. (uma fềmea, CAS). Costa RicA, Cartago: X-1958, N.L.H. Kranas leg. (uma fềmea, AMNH); Isla Nassau: New providence, 05-IV-1953, Van Voast-AMNH, E.B. Hayden leg. (uma fềmea, AMNH); Eleuthera Isl.: James Cistern, 01-IV-1953, Van Voast-AMNH, Hayden \& Giovannoti leg. (uma fềmea, AMNH); Berry Isl.: 30-IV-1953 (uma fêmea, AMNH). Guatemala, Nueva Concepcion: 50’, 17-VIII-1963, D.Q.Cavagnaro \& M.E. Irwin leg. (uma fêmea, CAS).

AGRADECIMENTOS. AOs curadores das seguintes instituições responsáveis pelo empréstimo do material: Sr. Julian Stark (AMNH): Sr. Donald Azuma (ANSP): Sr. Nigel P. Wyatt 
(BMNH); Drs Paul H. Arnaud Jr. e Norman D. Penny (CAS): Dr. M. Parrillo (FMNH): Drs Scott R. Shaw e Cleone T. Graham (MCZ): Dr. Robert W. Brooks (SMEK); Dr. F. Christian Thompson (USNM).

\section{REFERÊNCIAS BIBLIOGRÁFICAS}

AczéL, M. 1939. Das System der Familie Dorylaidae. Dorilaiden Studien I. Zool. Anz. 125: 15-23.

. 1940. Vorarbeiten zu Einer Monographie der Dorylaiden (Dipt.). Dorylaiden-Studien V. Zool. Anz. 132 (7-8): 140-169.

1948. Grundlagen Einer Monographie der Dorilaiden. Dorilaiden Studien VI. Acta zool. Lilloana 6: 5-168.

. 1952. Catalogo de la familia Dorilaidae (Pipunculidae) de la Region Neotropical. Revta Soc. ent. argent. 15: 237-251.

Ale-RochA, R. 1992. Redescrição de Tomosvaryella galapagensis (Curran, 1934) (Diptera: Pipunculidae). Bol. Mus. Para. Emílio Goeldi 8 (2): 319-321. Revisão do gênero Tomosvaryella Aczél da América do Sul. Revta bras.

Ent.: (no prelo).

COLE, F.R. 1923. Expedition of the California Academy of Sciences of the Gulf of California II. General report. Proc. Calif. Acad. Sci. 12 (25): 457-481.

. 1969. The flies of western North American. Pipunculidae. Univ. Calif. Press.

Collin, J.E. 1931. Diptera of Patagonia and South Chile. Platypezidae, Pipunculidae, 6 (2): 49-61.

Cresson, E.T. 1911. Studies in North American dipterology: Pipunculidae. Trans. Amer. Ent. Soc. 36: 267-329.

Curran, C.H. 1934. The Trempleton Crocker Expedition of the California Academy of Sciences, 1932, nr 13. Diptera. Proc. Calif. Acad. Sci. (4) 21 (13): 147-172.

Dalmau, P.A. \& I.G. ÁvilA. 1983. Lista anotada de los dípteros de Cuba. Ciudad de La Habana, Editorial Científico-Técnica, $201 \mathrm{p}$.

DE MEYER, M. 1989. Taxonomische, systematische en zoogeografische revisie van de genusgroep Cephalops Fallén (Diptera, Pipunculidae). Tese de Doutorado, não publicada, Universiteit Antwerpen.

HaRdY, D.E. 1940. Dorylaidae Notes and Descriptions (Pipunculidae-Diptera). J. Kans. Ent. Soc. 13: 101-114.

Sci. Bull. 29 (1): 1-231.

1948. Neotropical Dorilaidae (Pipunculidae) Studies, Part 1 (Diptera). Psyche 55 (1): 1-15.

(Pipunculidae-Diptera). Acta zool. Lilloana 10: 299-306.

. 1954. Neotropical Dorilaidae Studies, Part III. Brazilian species and a key to the know species of Dorilas Sens. Lat. Bol. Mus. Nac., n.s., Rio de 
Janeiro, 123: 1-60.

. 1963. Studies in Pipunculidae (Diptera) of Colombia. Proc. Hawaii. ent. Soc. 18 (2): 259-266.

. 1965a. The Pipunculidae of Argentina. Acta zool. Lilloana 19: 187-241. . 1965b. Neotropical Pipunculidae (Diptera) Studies, Part IV. Further studies of Brazilian species. Arq. Zool., São Paulo, 14 (1): 1-68.

- 1965c. A Catalogue of the Diptera of America North of Mexico. Agriculture Handbook 276. Washington, Unit.State Depart. Agric., 1696 p. 1966. Family Pipunculidae (Dorilaidae), In: N. PAPAVERO (ed.). A catalogue of the Diptera of the Americas South of the United States. 45: 1-15, São Paulo, Museu de Zoologia, Universidade de São Paulo.

Hough, G. 1899. Studies in Diptera Cyclorrapha 1. The Pipunculidae of the United States. Proc. Boston Soc. Nat. Hist. 29 (4): 77-86.

Koizumi, K. 1959. On four Dorilaid Parasites of the green rice leathopper, Nephotettix cincticeps Uhler. (Diptera). Scient. Rep. Fac. Agri., Okayama Univ., 13: 37-45.

LoEw, E. 1872. Diptera Americae Septentrionalis. Centuria decima. 16 (1): 87-88.

MCALPINE, J.F. 1981. Morphology and terminology, p. 9-63, In: J.F. MCALPINE (ed). Manual of Nearctic Diptera. Ottawa, Res. Brach, Agriculture Canada, vol. $1,574 \mathrm{p}$.

Rafael, J.A. \& M. DE MEYer. 1992. Generic classification of the family Pipunculidae (Diptera): a cladistic analysis. Journ. nat. Hist. 26: 637-658.

Scarbrough, A.G. \& L.V. Knutson. 1989. Asilidae, Bombyliidae, Conopidae, and Pipunculidae (Diptera) of Dominica, West Indies. Fla. Ent. 72 (3): 519-537.

Shannon, R.C. 1927. Some new Diptera from Argentina. Revta Soc. ent. argent. 1 (4): 31-42.

WALOFF, N. \& M.A. Jervis. 1987. Communities of Parasitoids associated with Leafhoppers and Planthoppers in Europe. Advances ecol. Res. 17: 281-402. Williston, S.W. 1896. On the Diptera of St. Vincent (West Indies). Trans. ent. Soc., London: 351-435.

YANO, K. 1979. Faunal and biological studies on the insects of paddy fields in Asia. Par II. Illustrated key to the Thai species of Pipunculidae (Diptera). Esakia. 13: 45-54. 